\title{
Evaluation of Closed and Open Reduction of Condylar Fractures
}

\author{
Sandhya R
}

\begin{abstract}
To evaluate the closed versus open reduction of condylar fracture. This review was to evaluate the main variable that determine the choice of method for treatment of condylar fracture: open or closed, pointing out their indications, contra-indications, advantage and disadvantage. The treatment of condylar process fracture has generated a great deal of discussion and controversy in oral and maxillofacial trauma and there are many different methods to treat this injury. For each type of condylar fracture, the technique must be chosen taking into consideration the presence of teeth, fracture height, patient's adaption, patient's masticatory system, disturbance of occlusion, functional deviation of mandible, internal derangements of the temporomandibular joint(TMJ) and ankylosis of joint with resultant inability to move the jaw, all of which are sequelae of this injury. Many surgeons seem to favor closed treatment with maxillomandibular fixation $(M M F)$,but in recent years,open treatment of condylar fracture with rigid internal fixation(RIF) has become more common.
\end{abstract}

Keywords: Mandibular condyle fractures, Mandibular condyle fracture surgery, open reduction, closed reduction

\section{Introduction}

Fracture is defined as a break in bone or cartilage.Although usually a result of trauma, a fracture can be the result of acquired disease of bone such as osteoporosis or of abnormal formation of bone in a congenital disease of bone such as osteogenesis imperfecta (brittle bone disease).

Fracture of the condylar process include superior,medial and inferior fractures and fractures of the condylar head.

\section{Classification of Condylar Fractures}

1. Unilateral or bilateral condylar fractures.

2. Rowe and Killey's classification

a. Simple fractures of condyle

b. Compound fractures of condyle

c. Comminuted fracture associated with zygomatic arch fractures.

3. Rowe and Killey's classification (1968)

a. Intracapsular fractures or high condylar fractures

b. Extra capsular or low condylar fractures.

4. Spiessel and Schroll classification (1972)

a. Nondisplaced fracture

b. Low neck fracture with displacement

c. High neck fracture with displacement

d. Low neck fracture with dislocation

e. High neck fracture with dislocation

f. Head fracture

1) Etiology of Condylar Fracture

- Intentional trauma-interpersonal violence/ fist fight,etc.

- Unintentional trauma- motor vehicular accidents, fall on the chin, sports injuries, industrial mishaps, etc.

Whenever a blow is received on the lateral side of face,the zygomatic arch protects the condyle and coronoid process.Under these circumstances, the arch may fracture and may be associated with fracture or dislocation of the condyle.

When the blow is received in the center of the chin,the distribution of force is equal to both the condyles, resulting in a bilateral indirect fracture through the necks, accompanied by a direct fracture at the symphysis.

\section{2) Clinical Features}

- Localized pain and swelling in the region of the TMJ

- Limitation of mouth opening

- Deviation upon opening towards the involved side.

- Posterior open bite on the contra lateral side.

- Blood in the external auditory canal.

- Pain on palpation over the fracture site.

- Lack of condylar movement upon palpation.

- Difficulty in lateral excursions as well as protrusion.

- Persistent cerebrospinal fluid leak through ear is indicative of an associated fracture of the middle cranial fossa

\section{3) Management}

- Non-surgical management of condylar fractures

- Surgical approach of the condyle.

\section{4) Non-Surgical Management}

Most cases of the condylar fractures are best managed through non-surgical means.No treatment is considered when no occlusal discrepancy or functional discrepancy exists. The obvious advantage is the avoidance of morbidity and complications associated with surgery.

\section{Surgical Correction of Condylar Fractures}

\section{1) Closed Reduction}

\section{Indications}

- Condylar neck fractures in children<15years

- Intra capsular fractures

- Very high condylar neck fractures without dislocation

- Grossly comminuted fractures and gun shot.

The mandible is manipulated so that the teeth are in normal occlusion, followed by mandibulo-maxillary fixation.

This is achieved by the use of

- Arch bars

- Cap splints

- Gunnings splint

- Bonded brackets 
- IMF screws

- Dental wiring

- Direct wiring

- Eyelet wiring

Treatment can be performed under GA or LA and when surgery is contraindicated.

\section{Disadvantage}

Due to prolonged immobilization of jaws patient complains of

- Panic

- Insomnia

- Phonetic disturbance

- Weight loss

- Physical discomfort

- Histologic changes in condylar head

- Difficulty recovering a normal range of jaw movement This has led some clinicians to seek alternative methods of treatment,including the use of rigid internal fixation.

\section{2) Open Reduction with Internal Fixation}

\section{Indications:}

\section{A) Limitation of Function Secondary to the Following: \\ - Fracture into the middle cranial fossa \\ - Foreign body within the joint capsule \\ - Lateral extracapsular dislocation of condylar head.} Other fracture dislocations in which a mechanical stop is present on opening which is confirmed by radiographically.

\section{B) Inability to Bring the Teeth into the Occlusion for Closed Reduction}

A variety of surgical approaches to the fractured condyle have been suggested,including;

- Intra oral

- Submandibular

- Retro mandibular

- Preauricular

- More recently endoscopic

The most important factor in determining the approach used is the level at which the fracture has occurred.

Modifying factor such as the degree of displacement or dislocation and the planned method of fixation may also have a bearing on the approach is selected.

\section{3) Endoscopically Assited}

- It reduces the risk to the facial nerve and minimize scarring

- Under vision and with special instruments the fracture is manipulated and reduced.

\section{4) Free Plating and Grafting}

This is used with severe extensive fractures / lesions in which a large portion of bone is lost.

\section{Discussion}

Despite a plethora of treatment guidelines, management of sub condylar fracture of the mandible remains controversial. During the past few decades, Closed reduction has been the preferred treatment [1]; however, closed treatment requires a period of MMF, followed by active physiotherapy [2].Also, long term complications such as pain, arthritis, open bite, deviation of the mandible on opening, inadequate restoration of vertical height of the ramus leading to malocclusion, and ankylosis can result from the closed reduction method [3]. Today for dislocated fractures,open approaches are considered as the treatment of choice for many units. However, for moderately displaced condylar fractures,open treatment is still controversial [4]. As expected, in the closed treatment group,shortening of the ascending ramus and angulation of the fragments remained basically unchanged after 6months. The patients in the open treatment group also reported better treatment results in terms of less pain and discomfort.Previously reported retrospective studies demonstrated a better anatomical position after operative treatment.However, there was no significant difference in the functional clinical results [5,6]. Palmieriet al. [7] reported that open reduction might produce functional benefits for patients with severely dislocated condylar process fractures, and Undt et al. [8] reported that ORIF allows appropriate anatomical repositioning and immediate functional movement of the mandible. Haug and Assael [9] showed no differences for maximum interincisal opening, deviation on opening, and occlusion between closed and open management groups after treatment.In a series of nonrandomized observations Ellis and Co-Workers compared open and closed treatment. Whilst there were no significant differences in bite force [10]. In terms of occlusion, Ellis et al. (2000) observed a higher rate of occlusal disturbances after closed treatment [11] and Throckmorton and Ellis 2000 11] and Palmieri et al. 1999 [7] found more favorable outcomes after operative treatment. In terms of facial asymmetry Ellis and Throckmorton (2000) observed a shorter posterior facial height on the injured side after closed treatment. Rasse et al. (1990) demonstrated better clinical results in retrospective study [12].Better result from open reduction suggest that this will be the current trend for the management of condylar fractures.

\section{Conclusion}

Open reduction and fixation is better than the closed reduction because in closed reduction treatment patient may have complication such as pain,arthritis, open bite,deviation of the mandible on opening and ankylosis.But in open reduction treatment patient have lesser pain and discomfort and immediate functional movement of the mandible is possible.

\section{References}

[1] Brandt MT, Haug RH. Open versus closed reduction of adult mandibular condyle fractures: a review of the literature regarding the evolution of current thoughts on management. J Oral MaxillofacSurg2003;61:1324-32.

[2] Suzuki T, Kawamura H, Kasahara T, Nagasaka H. Resorbable poly-L-lactide plates and screws for the treatment of mandibular condylar process fractures: a clinical and radiologic follow-up study. $\mathrm{J}$ Oral MaxillofacSurg2004;62:919-24.

[3] Iizuka T, Lädrach K, Geering AH, Raveh J. Open reduction without $\mathrm{f}$ ixation of dislocated condylar process fractures: long-term clinical and radiologic analysis. J Oral MaxillofacSurg1998;56:553-61. 


\section{International Journal of Science and Research (IJSR) \\ ISSN (Online): 2319-7064}

Index Copernicus Value (2015): 78.96 | Impact Factor (2015): 6.391

[4] Silvennoinen et al., 1994; Baker et al., 1998; Joos and Kleinheinz ,1998, Smets et al., 2003.

[5] Takenoshita y, Ishibashi $\mathrm{H}$, Oka M:Comparision of functional recovery after non surgical and surgical treatment of condylar fractures.J Oral MaxillofacSurg 48: 1191-1195,1990

[6] Hayward JR,Scott RF: Fractures of the mandibular condyle.J Oral MaxillofacSurg 51: 57-61, 1993

[7] Palmieri C, Ellis E 3rd, Throckmorton G. Mandibular motion after closed and open treatment of unilateral mandibular condylar process fractures. J Oral MaxillofacSurg1999;57:764-75.

[8] Undt G, Kermer C, Rasse M, Sinko K, Ewers R. Transoral miniplate osteosynthesis of condylar neck fractures. Oral Surg Oral Med Oral Pathol Oral RadiolEndod1999;88:53443.

[9] Haug RH, Assael LA. Outcomes of open versus closed treatment of mandibular subcondylar fractures. J Oral MaxillofacSurg2001;59:370-5.

[10] Ellis 3rd. E, Throckmorton GS: Bite forces after open or closed treatment of mandibular condylar process fractures.J Oral and MaxillofacSurg 59: 389-395,2001.

[11] Ellis 3rd E, Throckmorton GS: Throckmorton GS: Facial asymmetry after closed and open treatment of fractures of the mandibular condular process. $J$ Oral and MaxillofacSurg 58: 719-728,2000.

[12] 12). Rasse M, Beck H, FutterM:ErgebnissenachKonservativer und operativerVersorgung Von GelenKfortsatZfrakturen des UnterKiefurs. Z Stomatol 87: 215-225,1990 